\title{
TJGTPPOIDT
}

\section{Future of Range Management: A Student's View}

The future of range management belongs to those who are prepared for it! This preparation is by no means concluded when an individual finishes his formal schooling. It should, in fact must, continue throughout his career if he is to optimize his potential to his employer and to the future of range management. There is no magic hour nor an amount of schooling which can be declared "enough."

While the new man may lack experience, the more experienced individuals in the organization must not underestimate his ability or knowledge. New ideas must be given due consideration and if unacceptable, must be rejected with ample explanation; for several rejections without explanation-in other words, with no way to learn why or where he went wrong- could result in the "new blood" becoming stagnated and the potential for change dying with the youth's enthusiasm and along with it the future of range management! Young men, while a part of some organizational structure, must retain and jealously guard their right to critically analyze resource management policy. In fact they may, if given the opportunity to grow, develop ideas which influence the formation of new policy.

Not only must the professional critically analyze performance in the field but also preparation for his career. The student-even in our enlightened age-is more or less a captive audience during his academic years. To some degree he is

The author is a student, Washington State University, Pullman. The article is an invited paper, delivered November 21,1972 , at the annual meeting of the Pacific Northwest Section, Society for Range Management. molded. If he discovers after entering the profession that therc are flaws in the mold, he should not let allegiance or pride keep him blind to educational deficiencies, thus continuing harmful practice and producing others like himself. He should critically analyze himself and that which produced him and make known to the schools the weaknesses he has found.

We must be ever mindful of the changes which are taking place in our field. If was but a few years ago that range reconnaissance was done mainly from horseback or on foot. Today, although we still walk and ride horses, our work is made much more complex and demanding through the use of low altitude aerial photographs; and it has been suggested by some that in the not too distant future we may map vegetation types from photographs taken by satellites that are already circling the earth! These changes must continue to be incorporated into our educational curriculum to provide the student with an opportunity to study, first hand, these rapidly developing areas.

It is important to be aware not only of the rapidly changing technology with which we must work but also of the changes which are taking place within society. The general public, which until a few years ago was quite apathetic towards our public lands, has recently shown considerable interest in the way lands are managed, private as well as public. These people, for the most part, have just become aware of what the professional range manager has known for many decades. Ranchers and other professionals have been practicing common ecological principles for many years. Be that as it may, we must now meet the challenge of helping this interested public understand the basic concepts of resource management. We must not, no matter how clearly we see the fallacy in judgments or ideas, underestimate the power of emotional speeches, books, or other forms of communication. Emotional presentations could cause segments of this public to be misinformed about and opposed to the work to which we have dedicated our careers and our lives.

Perhaps we, the range managers, have been self-aggrandizing; perhaps our belief, that ecological principles on public lands originated with us, is erroneous. The New York Times on September 25, 1972, quotes federal administrators as saying that range managers will be replaced by natural scientists. Who are these natural scientists and what will be their source? We think of ourselves (today's students) as natural scientists, taught as students and trained as new employees by those whose experience in resource management expresses essentially all scientific application in that area. A better wording of an old saying might be: "Experience is not necessarily the best teacher, but it certainly makes the best teachers."

The Society for Range Mangement must play an ever increasing role in the future of range management. It must bring together these new thoughts and ideas. It must be the "common bond" which will help to keep range management a progressive field and those concerned with range management mindful that it is an everchanging field.-PAUL E. NYREN, Pullman, Washington. 